\title{
An evaluation of the effect of the chemical and mechanical surface treatment of the glass fibre posts on the retention of the composite resin core material: An in-vitro study
}

\author{
Rohit Singh ${ }^{1}$, Irfanul Huda ${ }^{2 *}$, Supriya Singh ${ }^{3}$, Aaysha Tabinda Nabi ${ }^{4}$, Jazib Nazeer $^{5}$ \\ ${ }^{1,5}$ lecturer, ${ }^{2,4}$ Reader, ${ }^{3}$ Private Practitioner, ${ }^{1,2}$ Dept. of Prosthodontics, ${ }^{3}$ Dept. of Oral Medicine \& Radiology, ${ }^{4}$ Dept. of \\ Periodontology, ${ }^{5}$ Dept. of Oral Pathology, ${ }^{1,2,5}$ Patna Dental College and Hospital, Patna, Bihar, ${ }^{4}$ Buddha Institute of Dental \\ Sciences and Hospital, Patna, Bihar, India \\ *Corresponding Author: Irfanul Huda \\ Email: drirfanul76@gmail.com
}

\begin{abstract}
Introduction: To study the effect of the chemical and mechanical surface treatment of the glass fiber posts on the retention of the composite resin core material

Aims \& 0bjectives: To evaluate the influence of glass fibre post surface treatment with hydrofluoric acid [HF], hydrogen peroxide [H2O2] air abrasion via $\mathrm{Al}_{2} \mathrm{O}_{3}$ and chemical treatment with Silane coupling agent on tensile bond strength with composite resin core material.

Results: tensile bond strength between the glass fiber post and the core material was maximum. And tensile bond strength was minimum those treated with $\mathrm{Al}_{2} \mathrm{O}_{3}$ and $\mathrm{H}_{2} \mathrm{O}_{2}$

Conclusion: The effects of twelve different surface treatments on the retention of a glass fibre post, and to recommend surface treatment measures that can provide better retention and can be used as an effective method for bonding glass fibre post to resin cement.
\end{abstract}

Keywords: Glass fiber, Core material, Surface treatment ( $\mathrm{HF}, \mathrm{H}_{2} \mathrm{O}_{2}$, $\mathrm{Al}_{2} \mathrm{O}_{3}$.

\section{Introduction}

The goal of dental treatment is to provide optimal oral health, esthetics and function. Therapeutic efforts should produce predictable treatment results that are easily maintainable and reliable over the long term. This objective applies to each tooth in the dentition and more importantly to the dentition itself.

The restoration of an endodontically treated tooth can be difficult, both diagnostically and technically, owing to the fact that much of all of the coronal tooth structure, which normally would have been used in the retention of a restoration, has been destroyed by caries, previous restorations, trauma and the endodontic access preparation itself. The longitudinal success of restorative or prosthetic rehabilitations of endodonticallly treated teeth depends on the quality of the restoration, on its clinical adaptation and on the health of the supporting tissue.

Prefabricated fibre reinforced composite (FRC) posts first introduced in 1990 are widely accepted today as a viable alternative to cast posts for the restoration of endodontically treated teeth. Luted inside root canals, the fiber posts provided retention to a core material, which is directly build upon it.

.The major advantage of fiber posts is their similar elastic modulus to dentine, producing a stress field similar to that of natural teeth, whereas metal posts exhibit high stress concentrations at the dentine interface. Clinical studies have demonstrated high success rates without the occurrence of root fractures. Moreover fiber posts are ready to use whereas the construction of a cast post and core is more time consuming and demands extra clinic and laboratory time.

M. Vano, et al.(2006) conducted a study on the adhesion between fibre posts and composite resin cores: and concluded that retention increased on various surface treatment as compared to the normal to treatment cases. ${ }^{1}$

Many studies have tested ways of improving the interface strength between the fibre post $\&$ the resin 
based materials. These methods can be mainly divided into 3 categories.

1. Treatment that result in chemical bond between the composite $\&$ the post.

2. Treatment that intend to roughen the surface of the glass fibre post.

3. The combination of above mentioned two methods.

Treatment of the post surface with Silane coupling agent has been widely practiced for enhancing fibre/ composite interfacial adhesion.

Goracci C, et al. (2005) conducted a study on the adhesion between fiber posts and composite resin cores: tensile bond strength with and without post Silianization and concluded that without silanization the adhesion was less as compared with the silanized group. ${ }^{2}$

Hydrofluoric acid, has been applied to etch fibre post surface and this procedure statistically increases the interfacial bond strength between the post and the composite.

Hayakawa T, et al. (1992) conducted a study on the influence of surface conditions and silane agents on the bond of resin to dental porcelain and concluded that bond strength increased with treatment with surface conditioning and silanization. ${ }^{3}$

Ishida $\mathrm{H}$ et al. (1985) conducted a study on structural gradient in the silane coupling agent layers and its influence on the mechanical and physical properties of composites and concluded that physical and mechanical properties changed on application of silane coupling agent. ${ }^{4}$

\section{Aim \& Objectives}

The present in vitro study was conducted with following aim \& objectives:

To evaluate the influence of glass fibre post surface treatment with hydrofluoric acid $[\mathrm{HF}](4 \%)$, hydrogen peroxide $\left[\mathrm{H}_{2} \mathrm{O}_{2}\right](24 \%)$ air abrasion via $\mathrm{Al}_{2} \mathrm{O}_{3}$ and chemical treatment with Silane coupling agent on tensile bond strength with composite resin core material.

To recommend a surface treatment or their combinations to improve the tensile bond strength between the glass fibre post \& commercially available composite resin core build up material for clinical application.

\section{Materials and Methods}

To evaluate the effect of the chemical and mechanical surface treatment of the glass fiber posts on the retention of the composite resin core material A comparative in vitro study was undertaken at the Department of Prosthodontics, Sardar Patel Post Graduate Institute of Dental and Medical Sciences, Lucknow. UP and Central Institute of Plastic Engineering and Technology Lucknow.

120 posts were taken according to the surface pretreatment including the control group (with no surface treatment). The maximum diameter of the fibre post will be $0.76 \times 2=1.67 \mathrm{~mm}$. They were made of unidirectional glass fibres bounded in a methacrylate resin matrix After the application of hydrogen peroxide $\& \mathrm{HF}$, all the posts were rinsed with water \& air dried.

After the application of sliane coupling agent, a single layer with brush on the post surface it were left to air dry for 60 seconds at room temperature.

The sand blasted group- the posts in this group were sand blasted with 100 aluminum oxide particles using an oral micro blaster 60 seconds at Sample dimension $=5 \mathrm{~mm}$ length $\times 5 \mathrm{~mm}$ width $\times 5 \mathrm{~mm}$ height

For core buildup each post was positioned upright on a glass slab, and secured with a drop of sticky wax. Now the core material was allowed to flow around the fibre post. Light curing was done for $5 \mathrm{~min}$ (each cycle was of $60 \mathrm{sec}$ ) Using a visible light curing unit with an output of $600 \mathrm{mv} / \mathrm{cm} 2$ for each increments.

Once the curing cycle was completed, the unit was detached from the glass slab and an additional $60 \mathrm{sec}$ irradiation was given from the bottom of the unit which will be towards the glass slab. The samples were mounted on the universal testing machine with one end holding the glass fibre post $\&$ the other end holding the composite core build up material with fibre post.

The sample were loaded in tension at a cross headSpeed of $0.5 \mathrm{~mm}$ per minute until failure occurred at the post composite interface. Bond strength was expressed in Megapascals (MPa), by dividing the load at failure by the bonding surface area. The 
observations were tabulated and subjected to two-way Anova statistical analysis.

\section{Results}

Tensile Strength of Group I (Control): Tensile strength of specimens of Group I ranged from 11.8612.87 MPa. Mean tensile strength of Group I specimens was found to be $12.60 \pm 0.30$ while median tensile strength was $12.68 \mathrm{MPa}$. Kolmogorov-Smirnov test showed that data was symmetric $(\mathrm{p}=0.200 ; \mathrm{NS})$.

Tensile Strength of Group II (Hydrofluoric Acid (60 sec.) and Silane Coupling Agent): Tensile strength of specimens of Group II ranged from 15.2915.98 MPa. Mean tensile strength of Group II specimens was found to be $15.62 \pm 0.21 \mathrm{MPa}$ while median tensile strength was $15.60 \mathrm{MPa}$. KolmogorovSmirnov test showed that data was asymmetric ( $\mathrm{p}=0.048$; Significant).

Tensile Strength of Group III [Sand blasting done with $\mathrm{A1}_{2} \mathrm{O}_{3}$ (60sec]

Tensile strength of specimens of group III ranged from 11.89-12.8 MPa. Mean tensile strength of Group III specimens was found to be $12.24 \pm 0.26 \mathrm{MPa}$ while median tensile strength was $12.25 \mathrm{Mpa}$. KolmogorovSmirnov test showed that data was symmetric $(\mathrm{p}=0.200 ; \mathrm{NS})$.

Tensile strength of group IV (Silane coupling Agent): Tensile strength of specimens of Group IV ranged from 13.12-13.95 $\mathrm{MPa}$. Mean tensile strength of Group IV specimens was found to be $13.67 \pm 0.31$ $\mathrm{MPa}$ while median strength was $13.83 \mathrm{MPa}$. Kolmogorov-Smirnov test showed that data was asymmetric ( $\mathrm{p}=0.017 ; \mathrm{NS})$.

Tensile strength of Group V $\left[\mathbf{H}_{\mathbf{2}} \mathrm{O}_{\mathbf{2}}(\mathbf{2 4 \%})\right]$ : Tensile strength of specimens of Group V ranged from 12.3513.5 Mpa. Mean tensile strength of Group V specimens was found to be $12.57 \pm 0.34 \mathrm{MPa}$ while median tensile strength was $12.45 \mathrm{MPa}$. KolmogorovSmirnov test showed that data was asymmetric ( $\mathrm{p}=0.001$; significant).

Tensile Strength of Group VI [HF (4\%)]: Tensile strength of specimens of Group VI ranged from 15.1$15.98 \mathrm{MPa}$. Mean tensile strength of Group VI Specimens was found to be $15.56 \pm 0.39 \mathrm{MPa}$ while median tensile strength was $15.58 \mathrm{MPa}$. Kolmogorov-
Smirnov test showed that data was asymmetric ( $\mathrm{p}=0.036$; Significant).

Tensile Strength of Group VII $\left[\mathrm{H}_{2} \mathrm{O}_{2}(24 \%)\right.$ and silanization]: Tensile strength of specimens of Group VII ranged from 16.26-17.3 MPa. Mean tensile strength of Group VII specimens was found to be $17.15 \pm 031 \mathrm{MPa}$ while median tensile strength was 17.24 MPa. Kolmogorov-Smirnov test showed that data was asymmetric ( $<<0.001$; significant).

Tensile Strength of Group VIII $\left[\mathrm{H}_{2} \mathrm{O}_{2}(24 \%)\right.$ and HF (4\%)]: Tensile strength of specimens of Group VIII ranged from 14.71-14.99 MPa. Mean tensile strength of Group VIII specimens was found to be $14.89 \pm 0.08 \mathrm{MPa}$ while median tensile strength was 14.90 MPa. Kolmogorov-Smirnov test showed that data was symmetric ( $\mathrm{p}=0.200 ; \mathrm{NS})$.

Tensile Strength of Group IX $\left[\mathrm{Al}_{2} \mathrm{O}_{3}\right.$ and $\mathrm{H}_{2} \mathrm{O}_{2}$ (24\%)]: Tensile Strength of Specimens of group IX ranged from 11.22-11.45 MPa. Mean tensile strength of Group IX Specimens was found to be $11.32 \pm 0.08$ $\mathrm{MPa}$ while median tensile strength was $11.33 \mathrm{MPa}$. Komogorov-Smirnov test showed that data was symmetric ( $\mathrm{P}=0.200 ; \mathrm{NS})$.

Tensile Strength of Group X [ $\mathrm{A1}_{2} \mathrm{O}_{3}$ and $\left.\mathrm{HF}(4 \%)\right]$ : Tensile strength of specimens of Group X ranged from 13.58-13.70 MPa. Mean tensile strength of Group X specimens was found to be $13.64 \pm 0.05 \mathrm{MPa}$ while median tensile strength was $13.64 \mathrm{MPa}$. KolmogorovSmirnov test showed that data was symmetric ( $\mathrm{p}=0.200 ; \mathrm{NS})$.

Tensile Strength of Group $\mathrm{XI}\left(\mathrm{A1}_{2} \mathrm{O}_{3}\right.$ and silane coupling agent: Tensile strength of specimens of Group XI ranged from 15.33-15.46 MPa. Mean tensile strength of Group XI specimens was found to be $15.39 \pm 0.05 \mathrm{MPa}$ while median tensile strength was 15.40 MPa. Kolmogorov-Smirnov test showed that data was symmetric ( $\mathrm{p}=0.200 ; \mathrm{NS})$.

Tensile Strength of Group XII $\left[\mathrm{A1}_{2} \mathrm{O}_{3} \mathrm{HF}, \mathrm{H}_{2} \mathrm{O}_{2}\right.$ and Silane coupling agent]: Tensile strength of specimens of Group XII ranged from 16.75-16.98 MPa. Mean tensile strength of Group XII specimens was found to be $16.90 \pm 0.07 \mathrm{MPa}$ while median tensile strength was $16.92 \mathrm{MPa}$. Kolmogorov- Smirnov test showed that data was symmetric ( $\mathrm{p}=0.177$; NS.) Data of Group II, Group IV, Group V, Group VI, and Group 
VII was found to be asymmetric hence non-parametric analysis plan was adopted.

\section{Comparison of Tensile strength among different} groups: Tensile strength of Group IX $(11.32 \pm 0.008)$ was found to be lowest while that of Group VII $(17.15 \pm 0.31 \mathrm{MPa})$ was found to be highest.

Analysis of Variance: Above plot shows that order of group IX was found to be lowest and order of Group I, Group III, Group IV, Group V and Group X were also of lower order while that of Group II, Group VI, Group VIII and Group XI were of overlap of interquartile values was observed between Group II and Group VI and between Groups I and Group V was found. No overlap of interquartile values among the groups was found. In group I and Group III extremes values (hollow circles) was observed and in Group V and VII outlier (asterisks) was also observed. Difference in tensile strength among the groups was found to be statistically significant $(\mathrm{p}<0.001)$.

\section{Discussion}

This in vitro study attempted to evaluate the effect of different surface treatment of glass fiber post on the retention of a composite resin core. Many studies have tested ways of improving the interface strength between the fibre post $\&$ the resin based materials. The methods can be mainly divided into 3 categories.

1. Treatmetns that result in chemical bond between the composite $\&$ the post.

2. Treatments that intend to roughen the surface of the glass fibre post.

3. A combination of the above two methods

M. Vano et al. (2006) conducted a study on the adhesion between fibre posts and composite resin cores and concluded that retention increased on various surface treatment as compared to the no treatment cases. ${ }^{1}$

Glass fiber post consists of glass fiber bundles embedded in a special composite material, which chemically bonds with the dental material used for cementation and core build-up. Glass fiber, as a braided plait in a multi-axial arrangement, gives superior resistance to bending and torsion forces than fibers in an ordinary axially parallel arrangement. Fiber content is approximately 65\%. In this study, a glass fiber post as braided plait in multi-axial arrangement was used.

This study evaluated the use of a singlecomponent Silane coupling agent with and without surface treatment. Silane coupling agents can achieve chemical bonds with $\mathrm{OH}$ - covered inorganic substrates such as glass. A chemical bond may be achieved between the core resin matrix and the exposed glass fibers of the post at the interface level. However, the interfacial strength is still relatively low when compared to the values normally achieved with coronal dentin or enamel, due to the absence of chemical union between the methacrylate-based resin composites and the epoxy resin matrix of fiber posts.

Goaracci C, et al. (2005) conducted a study on the adhesion between fiber posts and composite resin cores: tensile bond strength with and without post silanization and concluded that without silanization the adhesion was less as compared with the silanized group. $^{(2)}$

Hayakawa T, et al. (19992) conducted a study on the influence of surface conditions and Silane agents on the bond of resin to dental porcelain and concluded that bond strength increased with treatment with surface conditioning and silanization. ${ }^{3}$

In the present study, the Silane coupling agent was used and was also applied after surface treatment with $\mathrm{H}_{2} \mathrm{O}_{2}$ hydrofluoric acid and Air abraded with $\mathrm{A}_{2}{ }_{2} \mathrm{O}_{3}$.

The solution used in this study, is was a single phase pre-hydrolyzed solution containing $1.0 \%$ monofunctional $\quad \mathrm{y}$-methacryloxypropyltrimethoxySilane (y-MPS), 52\% ethanol, and $47 \%$ water. The Silane was applied in a single layer because, according to the results of an in vitro study, the formation of a multilayer surface could reduce the effectiveness of the Silane coupling agent.

Hydrogen peroxide $\left(\mathrm{H}_{2} \mathrm{O}_{2}\right)$ is commonly employed in immunological electron microscopy to partially dissolve the resin surface of epoxy resinembedded tissue sections, and expose tissue epitopes for immune-labeling enhancement. The etching effect of $\mathrm{H}_{2} \mathrm{O}_{2}$ depends on its capacity to partially dissolve the resin matrix, breaking epoxy resin bonds through a mechanism of substrate oxidation. A similar $\mathrm{H}_{2} \mathrm{O}_{2}$ etching procedure is employed in this study to improve the micromechanical retention between the epoxy 
resin matrix of fiber posts and methacrylate-based resin composites ${ }^{.5}$

Ishida $\mathrm{H}$ et al. (1985) conducted a study on structural gradient in the Silane coupling agent layers and its influence on the mechanical and physical properties of composites and concluded that physical and mechanical properties changed on application of Silane coupling agent. ${ }^{4}$ Vano et al. (2006) evaluate the influence of $\mathrm{H}_{2} \mathrm{O}_{2}, \mathrm{HF}$, silanization, and a bonding agent on the tensile bond strength of glass fiber posts to different composite resins. The authors concluded that treatment of glass fiber posts with $\mathrm{H} 2 \mathrm{O} 2$ was an effective method that can improve the clinical performance of methacrylate resin based glass fiber posts. ${ }^{1}$

A more aggressive etching procedure involves etching fiber posts with hydrofluoric acid. However, this technique considerably effected the integrity of the fiber posts. M. Vano et al. (2006) conducted study on glass fibre post in which hydrofluoric acid was used for conditioning methacrylate-based fiber posts: despite of the improvement in post-to-composite bond strength, a noteworthy surface alteration ranging from micro-cracks to longitudinal fractures of the fiber layer was detected. On the contrary, it was observed that $\mathrm{H} 2 \mathrm{O} 2$ etching is a considerably milder technique with the exposed glass fibers remaining smooth and leaving the underlying epoxy resin matrix intact after the etching procedures. ${ }^{1}$

Hydrofluoric acid selectively dissolves the glass component of the fibre post, producing an irregular pattern of micro-spaces on the post surface. This may increase the surface area and facilitate the penetration of composite, especially the flowable resin, into the micro- retention of the post surface. ${ }^{6}$

It is said that mechanical techniques (e.g. Sandblasting) are more effective than chemical techniques (e.g. etching with HF, Silane, and H2O2). Monticelli et al. (2006) stated that the mechanical techniques are too aggressive for fibre posts, and then can decrease the fibre post fit in the root canals. However, chemical treatment can also roughen the post surface and consequently increase its mechanical interlocking with composite resin core.5 In the present study, the posts in the group were sandblasted with 50um aluminium oxide particles using an oral microblaster for 60 seconds at $0.25 \mathrm{MPa}$ pressure from a 10 millimeter distance, and then rinsed with ethanol $(96 \%)$ and were gently air-dried. The ultrasonic cleaning was done to remove the aluminum oxide particles from the surface of the posts so that it would not hinder the retention of the posts. The airborne particles abraded posts were rougher and appeared to provide an increased surface area with improved mechanical interlocking for the resin cement. ${ }^{1}$

Balbosh and Kern (2006) conducted a similar study with air abrading the surface of the glass fibre posts and similarly concluded that by air abrading, the retention of the posts had increased considerably. ${ }^{7}$

A total of a 120 samples were prepared and divided into 12 groups. The characteristics of each group were as follows:

In control group. Glass fibre reinforced posts without any surface treatment, served as the control group. This group had the tensile bond strength of lower order as compared to the values achieved with other surface treatment done in this study. In the present study, the tensile bond strength of the glass fibre post without surface treatment (control group) was found to be between 11.86 to $12.87 \mathrm{MPa}$. Treatment done with HF (4\%) (60 seconds) and Silane Coupling Agent. In this group, the samples were treated with HF (4\%) for 60 seconds along with silanization. The interfacial strength increased considerably after this pre-treatment method, the reason being that $\mathrm{HF}(4 \%)$ dissolves the glass component of the fibre post thus producing an irregular pattern of microspace on the post. Silane coupling agents can achieve chemical bonds within $\mathrm{OH}$ covered inorganic substrate such as glass. Both of these methods intend to increase the bond between the glass fibre post and the resin core material. The result in the present study revealed that there was an increase in the tensile bond strength. The result varied from 15.29 to $15.98 \mathrm{MPa}$.

\section{Treatment done with Al2O2 50um at $0.25 \mathrm{MPa}$ for} sixty seconds. Air abrasion roughened the post surface and consequently increased the micromechanical interlocking between the post and resin core material. The tensile bond strength was of lower order, but was greater than the control group. The tensile bond 
strength value of this group varied from 11.89 to 12.80 MPa.

silanization was done with Silane Coupling Agent. In this group, the effects of silanization have been discussed before. The tensile bond strength range varied from 13.12 to $13.95 \mathrm{MPa}$. This value was greater than that of the control group but was less than that of control group II, in which sandblasting was done along with treatment of the glass fibre post with HF (4\%) (60 seconds).

samples were treated with $\mathrm{H} 2 \mathrm{O} 2$ (24\%). In this group, the $\mathrm{H} 2 \mathrm{O} 2$ breaks the resin matrix bond through the mechanism of substrate oxidation. The tensile bond strength of this group was of lower order, and varied from 12.35 to $13.50 \mathrm{MPa}$. Though the tensile bond strength was of lower order, it was greater than that of the groups treated with $\mathrm{H} 2 \mathrm{O} 2$ in conjunction with air abrasion with $\mathrm{A} 12 \mathrm{O} 3$.

samples were treated with HF (4\%).: In this group, the HF (4\%) breaks the integrity of the fibre post, thereby increasing the bond strength between the glass fibre post and composite resin core material. The tensile bond strength was of middle order, and varied from 15.90 to $15.91 \mathrm{MPa}$.

Treatment with $\mathrm{H} 2 \mathrm{O} 2$ and Silane coupling agent has been discussed earlier. The tensile bond strength of this group varied from 16.26 to $17.23 \mathrm{MPa}$. The tensile bond strength was greatly increased of this group as compared with other groups.

Treatment done with $\mathrm{H} 2 \mathrm{O} 2$ (24\%) and HF (4\%). The effect of both the chemical etchants has been discussed earlier. The results showed that the tensile bond strength of this group was of middle order, and varied from 14.71 to $14.99 \mathrm{MPa}$. This group showed that the tensile bond strength was greater than group $\mathrm{V}$ in which treatment was done with $\mathrm{H} 2 \mathrm{O} 2$ (24\%), but was similar to group VI, in which treatment was done with $\mathrm{HF}(4 \%)$.

Treatment with Al2O3 and $\mathrm{H} 2 \mathrm{O} 2$ (24\%). The effect of $\mathrm{Al} 2 \mathrm{O} 3$ and $\mathrm{H} 2 \mathrm{O} 2$ has been discussed earlier. The results showed that the tensile bond strength was of lowest order, meaning that it varied from 11.22 to 11.45 $\mathrm{MPa}$. The result obtained were less than the result obtained from the control group.

Treatment with Al2O3 and HF (4\%) was discussed earlier. The results obtained were of lower order, varying from 13.58 to $13.70 \mathrm{MPa}$. The result obtained was greater than the treatment group with $\mathrm{Al} 2 \mathrm{O} 3$ and $\mathrm{H} 2 \mathrm{O} 2$, indicating that $\mathrm{HF}$ had greater etching properties as compared with $\mathrm{H} 2 \mathrm{O} 2$.

Treatment with Al2O3 H2O2 (24\%) and HF (4\%). This group showed increased tensile bond strength as compared with other groups. The range of tensile bond strength was from 16.76 to $16.96 \mathrm{MPa}$, which was somewhat similar to group VII i.e. samples treated with $\mathrm{H} 2 \mathrm{O} 2$ and silanization.

\section{Conclusion}

On the basis of observations of the present study, the tensile strength of Group VII, that is, those treated with $\mathrm{H} 2 \mathrm{O} 2$ and Silane coupling agent, and Group XII, that is, those treated with $\mathrm{H} 2 \mathrm{O} 2 \mathrm{HF}$, and $\mathrm{Al} 2 \mathrm{O} 3$ in combination, proved to be the most effective in increasing the retention of the glass fibre endodontic posts.

\section{Source of Funding}

None.

\section{Conflict of Interest}

None.

\section{References}

1. M. Vano, C. Goracci, F. Monticelli, F. Tognini, M. Gabriele, F. R. Tay et al. The adhesion between fibre posts and composite resin cores: the evaluation of tensile bond strength following various surface chemical treatments to posts. Int Endod J 2006;39:31-9.

2. Goracci C, Raffaelli O, Monticelli F, Balleri P, Bertelli E, Ferrari $\mathrm{M}$ et al. The adhesion between fiber posta and composite resin cores: tensile bond strength with and without post silanization. Dent Mater 2005;21:437-44.

3. Hayakawa T, Horie K, Aida M, Kanaya H, Kobayashi T, Murata $\mathrm{Y}$ et al. The influence of surface conditions and silance agents on the bond of resin to dental porcelain. Dent Mater 1992;8:238-40.

4. Ishida H. Structural gradient in the silane coupling agent layers and its influence on the mechanical and physical properties of composites. In: Ihida H, Kumar G, eds Molecular characterization of composite interfaces. New York, NY, USA: Plenum Press 1985; pp. 25-50.

5. Monticelli F, Toledano M, Tay FR, Cury AH, Goracci C, Ferrari VM. Post- surface conditioning improves interfacial adhesion in post/core restorations. Dent Mater 2006;22(7):602-9. 
6. Balbosh A, Kern M. Effect of surface treatment on retention of glass-fibre endodontic posts. J Prosthet Dent 2006;95(3):218-23.

7. Albashaireh ZS, Ghazal M, Kern M. Effect of dentin conditioning on retention of airborne-particle-abraded, adhesively lued glass fiber-reinforced resin posts. $J$ Prosthet Dent 2008;100(5):367-73.

8. Ahed M. Al-Wahadni, Sami Hamdan, Mahmoud Al-Oniiri, Mohammad M. Hammad, Muhanad M. Hatamleh. Fracture resistance of teeth restored with different post systems: in vitro study. Oral Surg Oral Med Oral Pathol Oral Radiol Endod 2008;106:77-83.
9. Aida M, Hayakawa T, Mizukawa K. Adhesion of composite to porcelain with various surface condition. $J$ Prosthetic Dent 1995; 73, 464-70.

How to cite this article: Singh $\mathrm{R}$, Huda I, Singh $\mathrm{S}$, Nabi AT, Nazeer J. An evaluation of the effect of the chemical and mechanical surface treatment of the glass fibre posts on the retention of the composite resin core material: An in-vitro study. Ann Prosthodont Restor Dent 2019;5(4):114-20. 